\title{
Mudança no padrão territorial de shopping centers na metrópole fluminense: os shopping centers da porção leste.
}

Modification de la configuration territoriale des centres commerciaux à Rio de Janeiro metropolis: les centres commerciaux dans la partie orientale Cambio en el patrón territorial de los centros comerciales en la metrópolis de Río de Janeiro: los centros comerciales en la parte oriental

Change in the territorial pattern of shopping malls in Rio metropolis: shopping malls in the eastern portion

\section{Allex Ornellas}

\section{CpenEdition}

Journals

Edição electrónica

URL: http://journals.openedition.org/espacoeconomia/5250

DOI: $10.4000 /$ espacoeconomia.5250

ISSN: 2317-7837

\section{Editora}

Núcleo de Pesquisa Espaço \& Economia

Refêrencia eletrónica

Allex Ornellas, « Mudança no padrão territorial de shopping centers na metrópole fluminense: os shopping centers da porção leste. », Espaço e Economia [Online], 14 | 2019, posto online no dia 10 agosto 2019, consultado o 06 setembro 2019. URL : http://journals.openedition.org/ espacoeconomia/5250; DOI : 10.4000/espacoeconomia.5250

Este documento foi criado de forma automática no dia 6 Setembro 2019

(c) NUPEE 


\title{
Mudança no padrão territorial de shopping centers na metrópole fluminense: os shopping centers da porção leste.
}

\author{
Modification de la configuration territoriale des centres commerciaux à Rio de \\ Janeiro metropolis: les centres commerciaux dans la partie orientale \\ Cambio en el patrón territorial de los centros comerciales en la metrópolis de Río \\ de Janeiro: los centros comerciales en la parte oriental \\ Change in the territorial pattern of shopping malls in Rio metropolis: shopping \\ malls in the eastern portion
}

Allex Ornellas

\section{Introdução}

1 As transformações no espaço urbano que destacamos (formas comerciais) estão inseridas na produção de empreendimentos imobiliários na porção leste da metrópole fluminense ocorridas, desde o final dos anos 1980. Essa década marca a expansão da indústria de shopping center no Brasil, e no caso dessa região, teve inaugurado o seu primeiro shopping center no município de Niterói. As transformações que mencionamos se articulam em várias escalas, pois todo o estado fluminense modifica-se, principalmente, a partir de mudanças em suas bases produtivas nos anos 90 como tentativa de retomada do crescimento econômico estadual. Esse processo se intensifica na década seguinte. 0 período dos anos 2000 corresponde também a políticas públicas federais que incidiram nos extratos de rendimentos mais baixos da sociedade no qual, possibilitou o ingresso dessas camadas ao consumo. Esses extratos são maioria na metrópole estudada e assim, temos a formação de um mercado consumidor propenso ao consumo reificado existente nos shopping centers. Nesta perspectiva, o modelo de localização dessa forma comercial 
articula-se com as mutações sociais que se expressam pelo espaço da sociedade que está cada vez mais urbana. A relação entre comércio e cidade vem dos primórdios da civilização, sendo o shopping center mais um produto dessa relação.

2 A construção do excedente regular de produção é um marco histórico na sociedade, tendo em vista que, a partir da existência desse excedente, desenvolveu-se o sistema de troca mercantil capitalista. Contudo, a troca de produtos não é exclusividade da sociedade vigente. Existiram atividades comerciais datadas de épocas anteriores como: neolítico, antiguidade, idade média, ou seja, chamamos atenção acerca das atividades comerciais como correlatas da história da humanidade, sendo assim, em sociedades pré-capitalistas. A relação entre homens e trabalho - atividade desenvolvedora e inventiva do humano, historicamente, advém de antes do estabelecimento da divisão capitalista do trabalho. Nesse sentido, a história da troca correlaciona-se com o espaço-tempo do processo da constituição do ser humano. Essa constituição é permitida através do trabalho, todavia toda relação social, como é o trabalho, não é a-espacial. No âmbito do debate espacial, espaço e sociedade são indissociáveis, formando uma relação dialética. Portanto, o espaço é entendido por uma díade, onde é produto e condição da reprodução das relações sociais que os sujeitos estabelecem entre si, por meio do trabalho, para se apropriarem da natureza.

3 Ao entendermos que trabalho e sociedade também são inseparáveis, sinalizamos que a troca de produtos (fruto do trabalho) foi e será essencial no processo de humanidade e da própria reprodução das relações de produção, sinalizando que o trabalho é produtor das formas urbanas. As formas urbanas modificam a paisagem e imprimem um novo arranjo espacial, seguindo a racionalidade econômica mundial, projetando no espaço sua lógica hierárquica e desigual. Esse dinamismo altera valores sociais, inclui novos padrões culturais, ou seja, modifica ação e pensamento. Esses elementos estão no shopping center, indicando transformações no processo de reprodução da sociedade.

No presente artigo pretendemos refletir de forma crítica sobre a ligação entre comércio e cidade, onde a forma comercial é parte integrante do conjunto da produção geral da sociedade, essa sociedade que, atualmente, torna-se mundialmente urbana. Desta perspectiva, analisar a dispersão comercial através do novo momento histórico da produção do urbano - a metrópole. Analisar a metrópole permite-nos compreender como a troca de produtos se desenvolve na cidade e no espaço urbano-metropolitano. Deste modo, temos um desafio analítico e ao mesmo tempo potencializador que é compreender o papel da temática comércio e consumo no processo totalizante da produção do espaço (político, econômico e social).

\section{Comércio e consumo na cidade}

Estudar as formas comerciais e de consumo possibilita ampliar a reflexão crítica, a medida que, sob a égide do modo de produção capitalista, se estabelece uma relação íntima entre o desenvolvimento do comércio, consumo, modo de produção e sociedade. Essa afirmativa de vincular comércio e consumo aos aspectos fundamentais da reprodução da sociedade e do movimento geral do giro de capital está explícita na relação de determinação entre produção, distribuição, circulação, consumo e troca do sistema produtivo que interfere na formação social dos indivíduos. Além disso, nos permite explorar determinados momentos históricos no que tange: novos modos/hábitos de vida, sociabilidades, protótipos de consumo e paradigmas da estrutura social. Desta maneira, analisar o 
comércio e o consumo no bojo da reprodução das relações sociais capitalistas sinaliza para as transformações no espaço, na economia política, no urbano e na vida cotidiana da sociedade - real/virtual. E, no caso, estudar os shopping centers traz luminosidade acerca das questões referentes as atividades comerciais e das práticas de consumo acarretando mudanças nas condições materiais e imateriais da vida humana no mundo moderno. Essa relação entre comércio e cidade é apontada na seguinte citação.

o comércio foi peça fundamental para o nascimento das cidades e estas, permitiram o desenvolvimento das formas do comércio. Ao longo do tempo, esta relação de dependência e complementariedade só veio a se aprofundar, alcançando o patamar que encontramos hoje, início do século XXI, onde as formas materiais do comércio não tem existência a não ser pelo processo de reprodução do espaço urbano, ou melhor pela ampliação do modo de vida urbano a todas as partes do planeta. SILVA (2014, p.156)

6 A citação de Silva aponta o aprofundamento da correlação comércio, sociedade e espaço através do processo de urbanização, sendo estruturante de novas formas comerciais. $O$ referido autor observa que o comércio se amplia na/pela reprodução do espaço urbano, sendo o shopping center expressão fenomênica desse processo.

7 O movimento de instalação de shopping center não é algo apenas referente a mudanças na esfera comercial, pois a troca comercial articula-se com: produção, consumo, distribuição, circulação de pessoas, produtos e capital no/pelo espaço. Assim, necessário evidenciar transformações nas bases técnicas e no arranjo produtivo fluminense que estão associadas à políticas públicas de determinado governo federal brasileiro. Nesse sentido, fomenta-se a hipótese que o processo indica um novo momento na produção do espaço da metrópole fluminense. As transformações começaram aparecer a partir do final da década de 1990 e se intensificaram na segunda metade dos anos 2000, por políticas de reestruturação urbana que suscitaram a construção de empreendimentos imobiliários, entre os quais os shoppings que, como forma do comércio varejista, exercem papel importante na reconfiguração espacial.

O novo ciclo de produção de equipamentos comerciais está inserido no contexto do processo de produção do espaço da metrópole fluminense no século XXI, considerando-se a produção das periferias e dos municípios do interior da metrópole e de todo estado no tempo/velocidade do processo de urbanização no mundo contemporâneo. Assim, é preciso determinar as circunstâncias da construção dos shoppings no leste fluminense, não sem antes elucidarmos a implantação dessa forma comercial e os conceitos referentes a ela.

9 O nosso debate tem a intenção de investigar como essa forma comercial busca a sua renovação conceitual e prática atribuída à realidade social que vivemos. Assim, precisamos nos balizar por estudos anteriores sobre os processos que produzem os shoppings. Para isso valemo-nos das contribuições de pesquisadores que investigaram a questão:

Shopping Center significa um empreendimento imobiliário de iniciativa privada que reúne, em um ou mais edifícios contíguos, lojas alugadas para comércio varejista ou serviços. Distinguem-se umas das outras não somente pelo tipo de mercadoria que vendem (o tenant mix planejado pela empresa prevê a presença de várias lojas do mesmo ramo para permitir a compra por comparação), como também por sua natureza distinta (lojas-âncora e lojas de comércio especializado e serviços - que podem ou não pertencer a redes). A estrutura e funcionamento do empreendimento são controlados por um setor administrativo, necessário para o funcionamento eficaz do SC, o que significa dizer que é o setor cuja 
responsabilidade é zelar pela reprodução do capital da empresa. Além disso, está a presença de um parque de estacionamento, cujo tamanho depende do porte do empreendimento e da sua localização. Historicamente, esse é um fenômeno característico (ainda que não necessário) das sociedades capitalistas monopolistas. PINTAUDI (1992, p.15-16).

10 Nesse sentido, os shoppings são entendidos aqui como extensas, ou não, propriedades privadas de um ou mais edifícios, distribuídos majoritariamente pelo espaço urbano de forma planejada, sendo, de fato, empreendimentos imobiliários, pois visam a construir e comercializar as salas, via locação, para gerar lucro aos investidores. No processo é vital para os investidores a diversidade de lojas do comércio de varejo, lazer, entretenimento e dos serviços para acumulação do capital de forma contínua e ampliada. Além de importante locus ideológico, onde se reproduz a ideologia dos atores sociais hegemônicos, dissemina um padrão de consumo fetichizado, que intensifica a desigualdade/distinção social, pois exclui do bazar comercial do shopping aqueles que não têm o poder de compra necessário para aquisição das mercadorias comercializadas.

11 É importante ressaltar aqui as características dos shoppings no leste fluminense e, principalmente, nos municípios da extremidade dessa região. As suas construções atreladas com as transformações metropolitanas do estado fluminense, apesar de eles terem nexos produtivos que se repetem de um empreendimento para o outro, há características diferentes de acordo com o local de construção. Entre os empreendimentos há semelhanças e diferenças que podem ser físicas, de planejamento e de logística. Os shopping centers dessa região tem número de franquias, quantidade de lojas, lojas âncora, preço dos produtos, abl total construída e estacionamentos diferentes entre si e em comparação aos shopping centers da capital do estado.

Deste modo, a dispersão comercial revela-se como um processo que visa novas formas de acumulação através da produção de novos espaços segundo a lógica empresarial. As condições necessárias para a reprodução do capital são modificadas ao longo do tempo e efetivadas através do espaço. Nesse sentido, os shoppings representam o movimento de acumulação de capital dos grandes agentes capitalistas, que, em um dado momento da história do seu desenvolvimento, necessitaram do monopólio espacial e econômico para continuar a capturar, de forma privada, a riqueza produzida socialmente, ou seja, dar prosseguimento ao ciclo do capital pela apropriação privada dos meios de produção. 0 processo está vinculado à lei geral da sociedade capitalista: obter o lucro. Nesse momento, quando o monopólio das grandes corporações, aliado ao caráter ampliado do consumo ocorrido nesse período da história brasileira (anos 80), converge como fatores importantes para contextualizar o momento socioeconômico do surgimento dos shoppings no Brasil. Para Pintaudi (1992).

A presença de SC em diferentes regiões do País não é, pois fortuita do ponto de vista da distribuição e do crescimento da população. Além disso, a concentração de SC nos Estados do Rio de Janeiro e, fundamentalmente, de São Paulo, se deve ao fato de que esses Estados não somente tem um grande contingente populacional, como também, são grandes mercados consumidores, o que equivale a dizer que não é suficiente ter um número elevado de habitantes, mas também é necessário concentrar poder aquisitivo (PINTAUDI, 1992, p.22).

13 O momento de surgimento dos "templos da mercadoria" manifesta a estrutura socioeconômica desigual, pois são voltados para o consumo dos estratos sociais de maior rendimento. No Brasil, a década 1980 é entendida como período de expansão da indústria de shopping center, porém a maior parte da população brasileira ficou à margem desse 
processo em termos geográficos e sociais. Os shopping centers são instalados em um primeiro momento em lugares que comportam população com maiores rendimentos. A localização deles, no caso fluminense, deixa claro essa tendência, pois estão localizados no mesmo lugar onde se verifica o alto poder de compra dos fluminenses: a zona Sul da cidade do Rio de Janeiro. Entretanto, podemos observar uma mudança no padrão de localização dessa forma comercial correlacionada com o processo de expansão da metrópole. Esse processo pode ser observado através das estratégias capitalistas de atuação e das mudanças socioeconômicas que interferem no seu padrão territorial de localização, culminando com a instalação de shopping centers na zona norte da capital, no interior da metrópole e do estado. Para entendermos a conjugação desses processos torna-se necessário debater sobre o momento marcante da produção do espaço urbanometropolitano.

\section{Produção do espaço urbano-metropolitano}

Há uma interpretação ligada à forma material-histórica da cidade à metrópole, pois ambas, como estruturas urbanas, são produzidas e condicionantes das mudanças do modo de produção capitalista e representam acúmulos de tempos diversos no espaço social. A formação social, tanto da cidade, quanto da metrópole repercute essas mudanças pela penetração espacial das atividades econômicas como as da indústria, do comércio e da produção da riqueza em si. Diante disso podemos pensar na questão da problemática urbana e sua articulação com a generalização, de forma prática e ideológica das trocas no capitalismo em relação à reprodução da cidade e da metrópole.

o processo de urbanização da sociedade que configurou as metrópoles pode ser analisado por vários ângulos. De um lado, a metrópole estuda, pelo aspecto estrutural e conjuntural, o seu papel no território nacional incitado por um processo econômico em evidência e/ou dominante no espaço mundial. De outro lado, segundo Seabra (2011, p.55) concebe-se a "metrópole como fenômeno histórico-geográfico, político e social". Essa visão considera que as mudanças no tempo-espaço da cidade, ao longo da história, trouxeram a substituição do sentido no espaço urbano pelo sentido do mercado de negócios. Ocorreu uma transformação radical na formação social e, sobretudo, no espaço urbano. Nesse contexto produziu-se a metrópole como fruto do processo histórico da metamorfose da cidade, como expressão do aprofundamento do processo de urbanização da sociedade.

16 A forma da metrópole, antes concentrada, agora tem atributos que sinalizam para uma dispersão difusa, ou seja, sua dimensão territorial atual é expandida e desconcentrada, sendo difícil definir seus limites dinâmicos. 0 processo de expansão da escala territorial da metrópole revela um aspecto importante, pois, junto disso, há uma mudança nas funções das cidades com renovações e refuncionalizações para possibilitar a resolução da crise de acumulação do modo de produção capitalista. As três categorias estrutura, forma, e função -, conjugadas em uma visão analítica ampla, buscam a compreensão da totalidade pelo movimento dialético das relações sociais ao longo da história (Lefebvre, 2001, p.189). Desse modo, para elucidar a problemática da metamorfose da metrópole contemporânea como um produto social e condição espacial essencial para a reprodução do capital, encontramos suporte nas ideias de Lencioni (2011)

A forma que a metrópole assume, de maior escala territorial, ao expandir sua região, é central para a acumulação porque ela vem acompanhada da possibilidade de oferecer sobrevida às relações capitalistas, uma vez que a valorização imobiliária 
que acompanha o espraiamento territorial da metrópole se constitui numa das principais estratégias para a produção e concentração da riqueza social, uma vez, que o predomínio da descontinuidade é estratégico para a reprodução do capital. A sua forma descontínua, por assim dizer, é a expressão, no limite último, da força desmedida do espaço-mercadoria, instrumentalizado pela valorização imobiliária do capital." (LENCIONI, 2011, p.56)

17 A forma como a metrópole se reproduz remete à criação de possibilidades necessárias ao dinamismo econômico mundial, segundo Lencioni (2008, p.41), “à metrópole como sobrevida do capitalismo". Assim, o processo de produção do espaço urbanometropolitano é produto e condicionante do movimento de acumulação de capital atual, permitindo através de transformações no espaço social que o ciclo do capital se renove, dando uma nova vida as relações capitalistas de produção. Esse movimento macro se expressa na metrópole fluminense, principalmente, pelo processo de reestruturação produtiva. Na próxima parte cabe debatermos sobre o processo de expansão da metrópole no caso específico do estado fluminense, a seguir temos um mapa para nos localizarmos no espaço acerca dessa região:

\section{Dispersão comercial fluminense: os shopping center da porção leste}

Imagem 1 - região metropolitana fluminense:

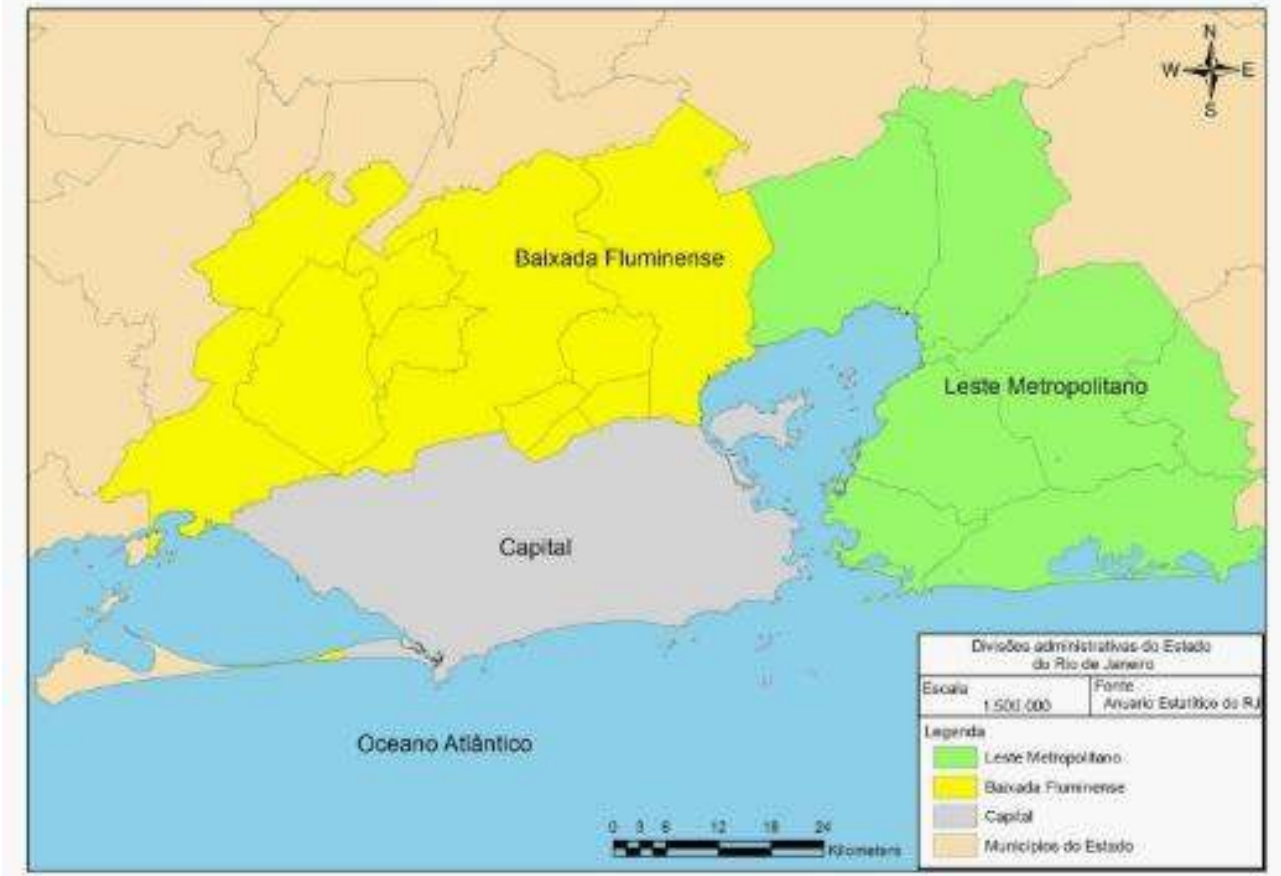

fonte: http://abeiradourbanismo.blogspot.com/2013/11

Segundo Oliveira (2012, p.51), o território fluminense vivencia algo novo em seu dinamismo, já que regiões do estado vêm modificando suas bases produtivas desde a década de 1990. As mudanças tornam-se mais impactantes quando tocam a metrópole do estado e toda a região metropolitana, dando início à reativação da economia em comparação com a estagnação trágica da década de 1980. As atividades petrolíferas na 
Bacia de Campos possibilitaram o crescimento econômico de cidades como Macaé, Campos e Rio das Ostras e com impactos na região metropolitana com a reabertura de estaleiros. O movimento foi incitado por políticas do governo federal. Com o decorrer do processo a importância do setor petrolífero e toda a sua estrutura acabou afetando todo o território fluminense. Nessa conjuntura o projeto do COMPERJ surgiu e determinou uma reorganização no uso do território da região metropolitana fluminense.

É importante ressaltar, que essa refinaria não elucida todos os processos e dinâmicas referentes ao nosso estudo, mas tem importância porque expressa um movimento de interiorização produtiva fluminense na região que nos debruçamos. Tal movimento, já era percebido como autores apontam desde a década de 1990, porém podemos observar implicações desse projeto no município de São Gonçalo situado na região leste.

Evidenciamos que as mudanças geram transformações no território, sendo necessários novos olhares técnicos e analíticos para esses novos usos do território, que estão alterando o espaço urbano fluminense, pois não são simplesmente de cunho industrial e econômico, mas crescem em demandas sobre os serviços e interferem na vida social. Nesse estágio a economia do estado não se faz somente pelo núcleo, em termos de visibilidade: aumentou a relevância do interior, que interage com o núcleo urbano, demonstrando uma integração entre ambos com a economia global. Oliveira (2012, p.143) mostra o principal projeto que recuperou a economia fluminense e, ao mesmo tempo, gerou integração em praticamente todo o estado.

Mas, sem dúvida, o grande marco do processo de recuperação da economia e das mudanças na organização social do território ocorreu com o anúncio feito pelo presidente Luiz Inácio Lula da Silva, em 2006, em solenidade no município de São Gonçalo, da decisão da Petrobras de instalar uma refinaria no município de Itaboraí e bases de operações e formação de mão de obra em São Gonçalo. Trata-se do Complexo Petroquímico do Rio de Janeiro (Comperj) (OLIVEIRA, 2012: p, 143)"

É necessário, mais uma vez, apontar que as mudanças ocorridas no leste metropolitano não são simplesmente impulsionadas pelo projeto petrolífero, embora haja, de fato, significativos impactos diretos e indiretos pelo território, que alteram a ordem econômico-social fluminense. Entretanto, o projeto e as mudanças no território fluminense fazem parte de um movimento mais amplo, inserido em uma dinâmica global de expansão da metrópole, produzindo novas relações no espaço. No caso estudado, observamos os empreendimentos imobiliários a leste da metrópole fluminense, mas é importante destacar que também ocorre uma reestruturação urbana a oeste e no interior do estado, com produção de novos conteúdos a partir da inserção das práticas imobiliárias e financeiras, além do setor industrial, articuladas à nova dinâmica do capital internacional. No caso do oeste fluminense, há a construção de condomínios industriais, residenciais e de shoppings, como destaca Oliveira, 2015. Na borda leste situam-se os projetos do COMPERJ, Arco Metropolitano, prédios comerciais novos e shoppings.

22 Assim, emerge a questão sobre os motivos da construção de shoppings e os efeitos desses empreendimentos imobiliários pelo espaço, tendo-se como hipótese que o papel do mercado imobiliário produz modificações nas formas citadinas e o comércio nas funções. O município de São Gonçalo (localizado na região leste da metrópole fluminense) é importante em relação a essa dinâmica por ser base logística do projeto do Comperj, como se pode verificar pela lei complementar número $1 / 2009$, que aprova a modificação do plano diretor municipal, tendo como objetivo central a criação de um polo técnico tendo em vista a cadeia do petróleo. A mudança no plano diretor do município foi sancionada 
pela, então, prefeita para produzir polos que promovam o desenvolvimento do projeto, como a formação de mão-de-obra via construção do polo de capacitação e polo de criação de feiras, eventos e negócios. No âmbito dos shopping centers, esse município teve dois shopping centers inaugurados em seus centros comerciais em um hiato apenas de 3 anos. O número maior de inaugurações nessa região da metrópole fluminense tem como período histórico o anúncio do COMPERJ, mas a própria atividade comercial já se expandia desde a década de 90 . Isso posto, analisamos as transformações no leste metropolitano fluminense, enfatizando os shoppings construídos nessa região no bojo da expansão da metrópole. 0 movimento do pensamento para compreender a instalação desses shoppings evoca um mergulho na história de sua construção, em especial, no caso fluminense. Assim, temos o Quadro 1 - shopping centers inaugurados no estado fluminense nos anos 80 .

Quadro 1 - shopping centers inaugurados no estado fluminense nos anos 1980.

\begin{tabular}{|c|c|c|c|}
\hline Shopping Centers & Municipio & Bairro & 7. Ano de inauguraçiv| \\
\hline Rio Sul Shopping Center & Rio de Janeiro & Botafogo (Zona sul) & \begin{tabular}{|r|}
1980 \\
\end{tabular} \\
\hline Barra Shopping & Rio de Janeiro: & Barra da Tijuca (Zona sul) & 1981 \\
\hline São Conrado Fashion Mall & Rio de Janeiro & São Conrado (Zona sul) & 1982 \\
\hline Rio Designer Center Leblon & Río de Janeiro: & Leblon (Zona sul) & 1983 \\
\hline Shopping Icarai & Niteroi (Leste Metropolitano) & Icarai (Bairro nobre de Niterói) & 1983 \\
\hline Shopping Center Bauhaus & Petropolis (Região Serrana) & Centro: & 1984 \\
\hline Casa Shopping & Rio de Janeiro: & Barra da Tijuca (Zona sul) & 1984 \\
\hline Resende Shopping & Resende (Região Médio-Vale Paraiba) & Centro & 1985 \\
\hline Plaza Shopping & Niteró (Leste Metropolitano) & Centro & 1986 \\
\hline Norte Shopping & Rio de Janeiro & Cachambi (Zona norte) & 1986 \\
\hline Madureira Shopping Rio & Rio de Janeiro & Madureira (Zona Norte) & 1989 \\
\hline Sider Shopping Center & Volta Redonda (Região Médio-Vale Paraiba) & Vila Santa Cecilia & 1989 \\
\hline Hiper Shopping Center $\mathrm{ABC}$ & Petrôpolis (Região Serrana) & Alto Da Serra & 1989 \\
\hline
\end{tabular}

Fonte: abrasce/reelaborado pelo autor - maio de 2017.

Quadro 2 - shopping centers inaugurados no estado fluminense nos anos 1990.

\begin{tabular}{l|l|lr|} 
& Tha Plaza Shopping & Jardim Carioca (Zona Norte) & 1992 \\
\hline Via Parque Shopping & Rio Janeiro & Barra Da Tijuca (Zona Sul) & 1993 \\
\hline Casa \& Gourment Shopping & Rio de Janeiro & Botafogo (Zona Sul) & 1994 \\
\hline Shopping Grande Rio & São João de Meriti (Baixada Fluminense) & Centro & 1995 \\
\hline Shopping Nova América & Rio de Janeiro & Del Castilho (Zona Norte) & 1995 \\
\hline Shopping Unigranrio & Duque de Caxias (Baixada Fluminense) & Jardim 25 de Agosto & 1995 \\
\hline Teresópolis Shopping Center & Teresópolis (Região Serrana) & Várzea & 1995 \\
\hline Top Shopping Center & Nova Iguaçu (Baixada Fluminense) & Centro & 1996 \\
\hline Boulevard Rio Shopping & Rio de Janeiro & Vila Isabel (Zona Norte) & 1996 \\
\hline Shopping Tijuca & Rio de Janeiro & Tijuca (Zona Norte) & 1996 \\
\hline Bay Market & Niterói (Leste Metropolitano) & Centro & 1997 \\
\hline West Shopping & Rio de Janeiro & Campo Grande (Zona Oeste) & 1997 \\
\hline Friburgo Shopping Center & Friburgo (Região Centro-Sul) & Centro & 1997 \\
\hline Barra Garden Shopping & Rio de Janeiro & Barra da Tijuca (Zona Sul) & 1997 \\
\hline Recreio Shopping & Rio de Janeiro & Recreio dos Bandeirantes (Zona Sul) & 1997 \\
\hline Shopping Piratas & Angra dos Reis (Região Costa Verde) & Centro & 1997 \\
\hline Cadima Shopping & Nova Friburgo (Região Centro-Sul) & Centro & 1998 \\
\hline Botafogo Praia Shopping & Rio de Janeiro & Botafogo (Zona Sul) & 1999 \\
\hline Shopping Città America & Rio de Janeiro & Barra da Tijuca (Zona Sul) & 1999 \\
\hline
\end{tabular}

Fonte: abrasce/reelaborado pelo autor - maio 2017 
Quadro 3 - shopping centers inaugurados no estado fluminense nos anos 2000.

\begin{tabular}{|c|c|c|c|}
\hline Leopoldina Shopping & Rio de Janeiro: & Penha (Zona Norte) & 2000 \\
\hline Passeio Shopping & Rio de Janeiro: & Campo Grande (Zona Norte) & 2000 \\
\hline Carioca Shopping & Rio de Janeiro & Vila da Penha (Zona Norte) & 2001 \\
\hline Center Shopping Rio & Rio de Janeiro & Jacarepaguá (Zona Oeste) & 2001 \\
\hline Vertical Shopping Center: & Rio de Janeiro: & Centro & 2002 \\
\hline Săo Gonçalo Shopping & Săo Gonçalo (Leste Metropolitano) & Boa Vista & 2004 \\
\hline Shopping Avenida 28 & Campo dos Goytacazes (Norte Fluminense) & Centro & 2006 \\
\hline Shopping Estação Itaipava & Petrópolis (Regiâo Serrana) & Itaipava & 2006 \\
\hline Shopping Leblon & Río de Janeiro & Leblon (Zona Sul) & 2006 \\
\hline Bangu Shopping & Rio de Janeiro & Bangu (Zona Oeste) & 2007 \\
\hline Caxias Shopping & Duque de Caxias (Baixada Fluminense) & Parque Duque & 2008 \\
\hline Shopping Macaé & Macaé (Norte Fluminense) & Alto Cajueiros & 2008 \\
\hline Cabo Frio Leste Shopping & Cabo Frio (Baixada Litorànea) & Centro & 2009 \\
\hline
\end{tabular}

fonte: abrasce/reelaborado pelo autor - maio 2017

Quadro 4 - shopping centers inaugurados no estado fluminense nos anos 2010.

\begin{tabular}{l|l|l|r|} 
Shopping Pátio Mix Costa Verde & Itaguai (Costa - Verde) & Santana & 2010 \\
\hline Partage Shopping São Goncalo & São Goncalo (Leste Metropolitano) & Centro & 2010 \\
\hline Via Brasil Shopping Center & Rio de Janeiro & Irajá (Zona Norte) & 2011 \\
\hline Shopping Jardim Guadalupe & Rio de Janeiro & Guadalupe (Zona Norte) & 2011 \\
\hline Shopping Resende & Resende (Região Médio -Vale Paraiba) & Paraiso & 2011 \\
\hline Shopping Uptown & Rio de Janeiro & Barra da Tijuca (Zona Sul) & 2011 \\
\hline Boulevard Shopping Campos & Campos dos Goytacases (Norte Fluminense) & Parque Leopoldina & 2011 \\
\hline Shopping Village Mall & Rio de Janeiro & Barra da Tijuca (Zona Sul) & 2012 \\
\hline Rio Designer Barra & Rio de Janeiro & Barra da Tijuca (Zona Sul) & 2012 \\
\hline Park Shopping Campo Grande & Rio de Janeiro & Campo Grande (Zona Oeste) & 2012 \\
\hline Shopping Metropolitano & Rio de Janeiro & Barra da Tijuca (Zona Sul) & 2013 \\
\hline Shopping Parque Lagos & Cabo Frio (Baixada Litorânea) & Parque Bule & 2013 \\
\hline Pátio Alcântara & São Gonçalo (Leste Metropolitano) & Alcântara & 2013 \\
\hline Parque Shopping Sulacap & Rio de Janeiro & Sulacap (Zona Oeste) & 2013 \\
\hline Convina Américas & Rio de Janeiro & Barra da Tijuca (Zona Sul) & 2013 \\
\hline Américas Shopping & Rio de Janeiro & Recreio dos Bandeirantes (Zona & 2014 \\
\hline Bossa Nova Mall & Rio de Janeiro & Centro & 2015 \\
\hline Itaborai Plaza & Itaborai (Leste Metropolitano) & Três Pontes & 2015 \\
\hline Outlet Premium Rio de Janeiro & Duque de Caxias (Baixada Fluminense) & Chácara Rio Petrópolis & 2015 \\
\hline Shopping Nova Iguaçú & Nova Iguaçú (Baixada fluminense) & Luz & 2016 \\
\hline Plaza Maricá Shopping & Maricá (Leste Metropolitano) & Centro & Projeto \\
\hline Alcântara Plaza Shopping & São Gonçalo (Leste Metropolitano) & Alcântara & Projete \\
\hline
\end{tabular}

Fonte: abrasce/reelaborado pelo autor - maio 2017.

23 A ampliação de shoppings, no Brasil, tinha, inicialmente, o foco locacional nas grandes capitais econômicas do país; no decorrer dos anos 80, porém, vemos a instalação deles em outros estados e em áreas de menor poder aquisitivo. Assim, podemos destacar o desempenho fluminense no setor imobiliário com várias construções dessa forma comercial nesse momento histórico. É importante perceber também a disposição geográfica dos empreendimentos pelo território fluminense nos anos 1980, uma vez que 5 deles estão em áreas de alto poder aquisitivo como os shoppings da zona Sul da cidade do Rio de Janeiro. A capital do estado abrigou 7 das 13 inaugurações e apenas duas, na zona Norte, área produzida como periferia. O estado fluminense conheceu, nessa época, um forte recuo no desenvolvimento industrial. O setor entrou em franca decadência. Quando o novo decênio entra, ainda vemos os efeitos da crise dos anos 80, mas a expansão industrial aponta para uma tentativa de retomada de crescimento nos anos 90. Nessa perspectiva, destacamos a recuperação econômica pela interiorização da indústria fluminense e pela atividade de extração petrolífera.

24 Nessa década foram 19 inaugurações de shoppings no estado fluminense, um número significativo de novos empreendimentos construídos. A região metropolitana fluminense destaca-se, pois, nesse período, foram 15 inaugurações. Os anos de 1990 e 1991 foram os 
únicos dessa década que não tiveram inaugurações dessa forma comercial. A década de 1990, para o estado do Rio de janeiro, foi o período de alteração profunda no plano econômico, com a viabilização de vários projetos de cunho neoliberal, através do capital privado nacional e internacional. A partir desses projetos neoliberais observa-se uma reestruturação do espaço fluminense, principalmente no setor industrial, com a interiorização do parque industrial como forma de reativar a econômica.

Segundo Limonad, (1996, p.21) ocorre um processo de interiorização populacional, de investimentos e produtiva em direção ao interior do estado fluminense nessa década. A tendência de interiorização das atividades produtivas e da população se faz, não só distante dos limites físicos do núcleo urbano fluminense, mas ocorre uma interiorização na própria região metropolitana. No contexto dos shoppings observamos, nos anos 90 , que a zona Sul da capital fluminense ainda desempenha um papel de atrair shoppings, mas já ocorre uma elevação no número de inaugurações na baixada fluminense, zona Norte da capital, Oeste e Leste metropolitano, caracterizando um novo momento no modelo de localização de shopping center no estado fluminense. Deste modo, a partir dessa década há uma mudança nas estratégias de localização, uma vez que os lugares de menor poder aquisitivo se tornaram atraentes pela estabilidade econômica do Brasil, pós década de 1980 e, principalmente, no caso fluminense, pelo crescimento da importância da cadeia do petróleo, com os dividendos dos royalties recebidos por diversos municípios do estado. E, nessa conjuntura, outros espaços recebem um número maior de instalação de shoppings.

Os anos 2000 correspondem, no âmbito nacional, a um período de políticas progressistas de inclusão social, aumento do crédito, geração de empregos e aumento das rendas das classes média e baixa. Essas medidas aliadas à expansão de investimentos produziram uma condição favorável ao dinamismo do mercado interno. O conjunto dos fatores proporcionaram uma elevação do padrão de consumo de boa parcela da população brasileira. A maior capacidade de consumo foi vista, principalmente, pelas camadas menos abastadas, no processo que se desenvolveu a partir de políticas de valorização do salário mínimo, diminuição gradativa da taxa de juros e mudanças institucionais que viabilizaram operações de crédito para as camadas de menor poder aquisitivo da população. A taxa de desemprego decaiu para apenas um dígito, dado que se relaciona com o desempenho do mercado interno, produzindo um aumento na geração de emprego. O governo federal dessa época produziu transformações que modificaram razoavelmente a distribuição de renda e as disparidades econômicas entre as regiões do Brasil. Foram transformações que produziram uma conjuntura, em que as classes sociais E, D e C brasileiras tiveram acesso a bens de consumo e melhor qualidade de vida, pela ampliação da capacidade de compra. Para decifrar as estratégias locacionais para a construção de shoppings, apoiamo-nos em Pintaudi (1992).

No fundo, trata-se de uma localização estratégica em relação ao mercado consumidor. Aliás, é sempre esta a questão fundamental, quando se trata de vendas a varejo. Porém, no caso do SC, o fato de se ter que reproduzir um grande capital implica a existência de um grande mercado consumidor, o que em outras palavras significa dizer que a estratégia é outra, já que envolve a presença de um mercado metropolitano e/ou regional (PINTAUDI, 1992, p,30).

Segundo a referida autora o mercado consumidor é elemento essencial para instalação da forma comercial shopping center. Esse fator se liga ao crescimento dos vínculos empregatícios dos anos 2000 como momento de crescimento da renda das camadas de menores rendimentos no Brasil. As transformações no território fluminense, a partir dos 
anos 2000, promoveram alterações econômicas e distribuição populacional, seguindo a localização dos investimentos, pois foi a reorientação espacial dos investimentos que provocou a emersão de novas áreas de atração populacional e econômica. Esse processo, que já era sinalizado na década anterior, nos anos 2000 se consolida. As regiões com maior número de investimentos tornaram-se alternativas de moradia e de inserção no mercado de trabalho, além de condicionarem a reestruturação produtiva e espacial do estado fluminense. Destacam-se, nesse contexto, as regiões: Norte Fluminense, Médio Paraíba, Baixadas Litorâneas e Região Metropolitana. O extrativismo mineral na região Norte, tendo a cidade de Campos como município detentor da maior bacia de extração de petróleo do Brasil, teve índices de crescimento econômico elevado, mas a base logística dessa atividade pertence aos municípios de Macaé e Rio das Ostras, que tiveram um aumento populacional significativo a partir das atividades referentes à extração mineral. A extração de petróleo na Bacia de Campos e sua influência na Baixada Litorânea nesse período fomenta o cenário da construção dos shoppings: Shopping Center Avenida 28, em Campos, Shopping Macaé e Cabo Frio Leste Shopping Center. As datas das inaugurações deles correspondem à época de aumento dos investimentos nesses municípios decorrentes da exploração do petróleo no Norte Fluminense, onde foi inaugurado o Shopping Center Avenida, localizado no município de Campos dos Goytacazes.

Nesse período ocorreram 13 inaugurações de shoppings no estado, com destaque para apenas uma inauguração da zona Sul. Assim, podemos observar um movimento em direção aos municípios do interior e da franja interior metropolitana de inaugurações, o que corresponde à reestruturação regional fluminense com o crescimento da população $\mathrm{e}$ de investimentos para fora da capital e no entorno metropolitano. As mudanças regionais, segundo o novo dinamismo econômico é uma construção histórica iniciada nos anos 1990, que, direta ou indiretamente influencia a construção de shoppings nas áreas que receberam mais investimentos, pois essa nova dinâmica fomentou maior circulação de capital nessas áreas específicas do território.o quadro 4 é fundamental para este trabalho, pois aponta, no tempo e no espaço, o movimento que baliza a nossa hipótese acerca da produção do espaço do leste metropolitano fluminense, uma vez que mostra a construção de shoppings, em maior número, nessa região. A construção desses empreendimentos não foi apenas nessa região, haja vista que municípios localizados nas regiões do interior do estado, também receberam investimentos, cresceram economicamente e tiveram inaugurações dessa forma comercial no período: 20 inaugurações de 2010 até o presente momento, com dois projetos a serem concluídos exatamente na região que estudamos. 
Gráfico 1 - número de lançamentos de shoppings no estado fluminense.

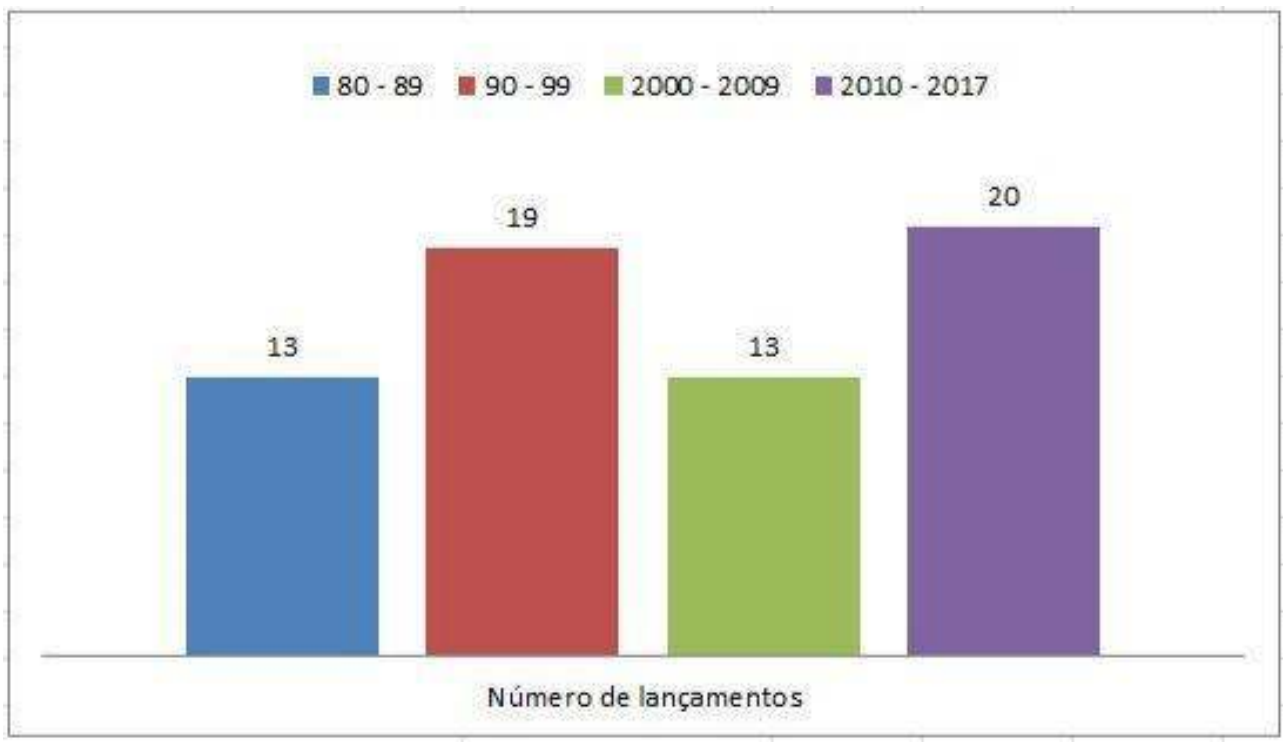

Fonte: abrasce/reelaborado pelo autor - maio 2017.

O gráfico 1 permite inferir que as décadas 1990 e de 2010 até recentemente são períodos que tiveram o maior número de lançamentos no estado. A década de 1990 destaca-se como o primeiro período de inserção de lugares de rendimentos menores na lógica de consumo dos shoppings, com um número maior em municípios e bairros da cidade do Rio de Janeiro com rendimentos médios e baixos. No período de 2010 até a atualidade, a periferia da metrópole se insere como mercado consumidor significativo, devido ao seu contingente populacional e aumento de renda. Esses fatores são analisados pela indústria de shoppings, assim como as características sociais dos municípios, onde as políticas referentes ao estado fluminense, principalmente relacionadas a interiorização das bases técnicas e de sua força produtiva, são importantes para a produção das condições socioeconômicas e das estratégias capitalistas de localização de empreendimentos imobiliários.

\section{Considerações finais}

Portanto, entendemos que o movimento da indústria de shopping center no espaço urbano fluminense tem sua expansão na mesma época do caso brasileiro, tendo a capital do estado e, especificamente, a zona sul da capital como local da gênese de instalação. Ao final da década de 80 vemos uma pequena mudança, direcionando essa forma comercial para locais que não tem o mesmo extrato de rendimento que a zona sul. Esse processo ganha força na década de 1990 e se consolida nas décadas seguintes.

31 Na busca pelas circunstâncias e motivos que expliquem a construção dos shoppings no leste fluminense, precisamos entrelaçar as escalas nacional, regional e global. Então, a passagem do regime fordista para o flexível provoca a reestruturação da produção, que se realiza no/pelo espaço, com mudanças nas condições de trabalho e nas características de organização, permitindo o surgimento de novos parâmetros tecnológicos e locacionais para a instalação de indústrias e investimentos. No momento em que essa conjuntura se expande como forma de produzir novas condições para o capital se reproduzir, as 
extremidades da metrópole e o interior fluminense se inserem nessa dinâmica. No caso fluminense, o processo remete à interiorização da produção como tentativa de retorno do crescimento econômico estadual. Com isso, vemos projetos públicos e privados de vários setores investindo seletivamente em algumas regiões do estado fluminense. $O$ estado do Rio de Janeiro gradativamente viu crescer a participação da cadeia do petróleo em sua economia, com influência na periferia metropolitana pela instalação de projetos referentes a esse setor e a setores ligados de forma indireta. São projetos como os que já foram citados acerca do Leste Metropolitano, mas a porção Oeste também passou por processos similares, e isso podemos observar no trabalho de Oliveira (2015).

O leste metropolitano teve inaugurações desde o final da década de 80 , com os primeiros shopping centers localizados no município de Niterói. Sãos nos anos 2000 que os municípios de São Gonçalo e Itaboraí recebem esses empreendimentos, um detalhe importante foi que a partir do final da primeira década dos anos 2000 vemos a construção desses empreendimentos de forma mais destacada. Isso pode ser observado por dois empreendimentos em São Gonçalo e um em Itaboraí. Os shopping centers nessa região são: Plaza Shopping, Bay Market, Niterói Shopping (Shopping centers do município de Niterói); São Gonçalo Shopping, Partage Shopping São Gonçalo, Pátio Alcântara (Shopping centers do município de São Gonçalo); Itaboraí Plazza (Shopping center do município de Itaboraí. Segundo abrasce (associação brasileira de shopping center), esses shoppings têm características de tipo tradicional, com porte regional e/ou pequeno. A maioria desses empreendimentos são de porte médio no leste fluminense, mas o Plaza Shopping e o São Gonçalo Shopping dispõem de uma abl (área bruta locável) maior. Outro fator que contribui para análise é o número de lojas na associação brasileira de franchising. Esse número difere daqueles dos shoppings no estado de São Paulo e aos da Zona Sul da capital fluminense, por exemplo, pois a maioria das lojas dos shoppings são associadas e, no caso do Leste Metropolitano Fluminense, vemos um número reduzido, com exceção do Plaza Shopping. É importante ressaltar a intencionalidade das empresas em não se cadastrarem, tendo em vista, que essa prática onera seus custos. Ao se cadastrar na Associação Brasileira de Franchising a empresa é obrigada, por contrato, a pagar algumas taxas.

Nos empreendimentos temos lojas franqueadas nacionais, em sua maioria, que atuam em escala nacional, regional e local, com valor para investimento inicial não tão alto em comparação com as grandes franquias localizadas nos shoppings das grandes cidades, segundo trabalho de campo realizado em maio de 2017. Alia-se a isso, a questão do espaço reduzido das salas locadas para essas franquias, principalmente, nos shopping centers em São Gonçalo, embora possamos ver salas de porte médio no Partage Shopping como no caso das suas lojas âncora. O Pátio Alcântara tem características distintas das definições teóricas sobre shopping, pois não tem estacionamento. A sua área bruta passível de locação, o número baixo de lojas e de lojas cadastradas na associação de franquias apontam para o seu pequeno porte como empreendimento do ramo. As marcas encontradas nele não são de grande expressão no cenário varejista internacional, pois estão voltadas para o público de menor poder aquisitivo. Desta maneira, nossa hipótese sobre esses empreendimentos remete que os shoppings construídos no leste da metrópole são majoritariamente populares. As características das lojas e as dimensões dos mesmos indicam que a indústria de shoppings não segue uma uniformidade completa, haja vista as diferenças entre eles, que se adaptam ao espaço local e ao público alvo. Os elementos significativos acerca desses Shopping Centers são: sua data de inauguração e sua 
localização, pois sinaliza o processo de expansão da metrópole articulado ao consumo, que significa a expansão do setor de comércio e serviços como um elemento da reprodução da sociedade. Os anos 1990 e 2000 são períodos com inaugurações de shoppings na Baixada Fluminense, Zona Oeste, porção oeste e leste da metrópole fluminense, com o incremento de grandes equipamentos comerciais. Outro período referente a esse processo pode ser visualizado a partir da segunda metade dos anos 2000, graças à influência da euforia produzida pela construção da refinaria do COMPERJ e seus impactos diretos e indiretos sentidos em São Gonçalo. 0 crescimento do comércio e dos serviços no cenário econômico também se configura como um fator estruturante da expansão da indústria de shopping center na metrópole.

Segundo esse trabalho, os fatores que produziram esses empreendimentos estão ancorados por uma mudança na ordem econômica- social fluminense vivia desde a década de 90 aliada à conjuntura política brasileira dos anos 2000, na qual produziu nas extremidades da metrópole o no interior do estado o principal fator de atração de shopping center - mercado consumidor.

\section{BIBLIOGRAFIA}

ANDRADE, Charles Albert de. Shopping Center também tem memória: uma história esquecida dos shoppings nos espaços intra-urbanos do Rio de Janeiro e São Paulo nos anos 60 e 70. Dissertação Universidade Federal Fluminense, 2009.

EGLER, Tamara Tania Cohen; TAVARES, Hermes Magalhães (Ogs). Política pública, rede social e território. Rio de Janeiro: Letra Capital, 2012.

LEFEBVRE, Henri. A revolução urbana. 3ed. Belo Horizonte: Ed. UFMG, 2008.

LEFEBVRE, Henri. O direito à cidade. 5ed. São Paulo: Centauro, 2001.

LENCIONI, Sandra. A metamorfose de São Paulo: o anúncio de um novo mundo de aglomerações difusas. In: Revista Paranaense de desenvolvimento. Curitiba, n.120, jan./jun. 2011, p.133-148.

LENCIONI, Sandra. Da Metrópole como estratégia desenvolvimentista à metrópole como sobrevida do capitalismo. In: PEREIRA, Paulo César Xavier \& HIDALGO, Rodrigo. Producción inmobiliaria y reestructuración metropolitana en América Latina. Santiago: PUC-Chile, 2008, p. 41-54.

LIMONAD, Ester. Os lugares da urbanização: O caso do interior fluminense. Tese (doutorado) FAUUSP - São Paulo, 1996.

OLIVEIRA, Floriano José Godinho de. Reestruturação produtiva, território e poder no Estado do Rio de Janeiro. Rio de Janeiro: Garamond, 2008.

OLIVEIRA, Leandro Dias De. A emersão da região logístico-industrial do ExtremoOeste Metropolitano Fluminense: reflexões sobre o processo contemporâneo dereestruturação territorial- produtiva. In: Revista Espaço e Economia, ano IV - número 7, 2015.

PINTAUDI, Silvana Maria. Os supermercados na Grande São Paulo: Contribuição ao estudo da transformação do comércio varejista de gêneros alimentícios nas grandes metrópoles. 
Dissertação (Mestrado em Geografia) - Faculdade de Filosofia Letras e Ciências Humanas, Universidade de São Paulo, São Paulo, 1981

PINTAUDI, Silvana Maria; FRÚGOLI, Heitor J. (Ogs) Shopping Center: espaço, cultura e modernidade nas cidades brasileiras. São Paulo: Editora da Universidade Estadual Paulista, 1992.

SEABRA, Odette Carvalho de Lima. A produção do espaço urbano: abordagens e método de análise. In: Oliveira et alli. (Org) Geografia urbana: ciência e ação política/ Rio de Janeiro: Consequência, 2014, p.67-83

SEABRA, Odette Carvalho de Lima. De cidade à Metrópole. In: Revista Geografares, n 9 , p.49-79, jul./Dez., 2011.

SILVA, Carlos Henrique Costa Da. Estudos sobre o comércio e o consumo na perspectiva da geografia urbana. Revista Geosul, Florianópolis, v. 29, n. 58, p 149-178, jul./dez. 2014.

\section{RESUMOS}

$\mathrm{O}$ presente texto pretende investigar e compreender as mudanças no padrão territorial das formas comerciais, especialmente shopping centers na metrópole fluminense. A nosso ver, o modelo de localização desses empreendimentos se altera, principalmente, a partir da década de 1990, no caso fluminense, tendo similitudes com o processo de reestruturação produtiva e urbana vivida do referido estado em várias escalas. o ponto de partida é a relação histórica entre comércio e cidade, tendo em vista que essa relação, sinaliza à própria constituição da humanidade ao longo do tempo. O objeto discutido é um equipamento comercial marcante na paisagem urbana brasileira desde os anos 1980, dando destaque aos shopping centers do leste da metrópole fluminense. Tal região, desde o período citado, tem em seu território essa forma comercial, mas suas inaugurações ao longo dos anos expressam mudanças significativas no que diz respeito ao espaço/tempo da vida urbana fluminense.

Ce document a pour objectif d'analyser et de comprendre les changements intervenus dans la structure territoriale des formes commerciales, en particulier les centres commerciaux de la métropole de Rio de Janeiro. À notre avis, le modèle d'implantation de ces entreprises a changé, principalement à partir des années 90 dans le cas de Rio de Janeiro, présentant des similitudes avec le processus de restructuration productive et urbaine de l'État à plusieurs échelles. Le point de départ est la relation historique entre le commerce et la ville, considérant que cette relation est un signal à la constitution propre de l'humanité à travers le temps. L'objet discuté est un équipement commercial remarquable dans le paysage urbain brésilien depuis les années 1980, mettant en valeur les centres commerciaux de l'est de la métropole de Rio de Janeiro. Depuis cette période, cette région a cette forme commerciale sur son territoire, mais ses inaugurations au fil des ans expriment des changements importants en ce qui concerne l'espace / le temps de la vie urbaine à Rio.

El presente texto pretende investigar y comprender los cambios en el patrón territorial de las formas comerciales, especialmente centros comerciales en la metrópolis fluminense. A nuestro ver, el modelo de localización de esos emprendimientos se altera, principalmente, a partir de la década de 1990, en el caso fluminense, teniendo similitudes con el proceso de reestructuración productiva y urbana vivida de dicho estado en varias escalas. El punto de partida es la relación histórica entre comercio y ciudad, teniendo en vista que esa relación, señala a la propia constitución de la humanidad a lo largo del tiempo. El objeto discutido es un equipamiento comercial destacado en el paisaje urbano brasileño desde los años 1980, dando destaque a los centros comerciales del este de la metrópolis fluminense. Tal región, desde el período citado, 
tiene en su territorio esa forma comercial, pero sus inauguraciones a lo largo de los años expresan cambios significativos en lo que se refiere al espacio / tiempo de la vida urbana fluminense.

The present text intends to investigate and understand the changes in the territorial pattern of installation of commercial forms, especially, shopping centers in the metropolis of Rio de Janeiro. In our view, the model of location of these enterprises changes, mainly, from the 1990s in the case of Rio de Janeiro, with similarities to the process of productive and urban restructuring of this state at various scales. The starting point is the historical relation between commerce and city, considering that the very constitution of humanity implies in the transformations of the exchanges of products. The object discussed is a remarkable commercial equipment in the Brazilian urban landscape since the 1980s, especially the shopping centers in the east of the Rio de Janeiro metropolis. Such a region has had this commercial form in its territory, but its inaugurations, over the years, express significant changes in space - time of urban life in.

\section{ÍNDICE}

Mots-clés: centre commercial; metrópole; fluminense orientale

Keywords: shopping centers; metropolis; eastern fluminense

Palabras claves: centro comercial; metrópoli; leste fluminense

Palavras-chave: shopping center; metrópole; leste fluminense

\section{AUTOR}

\section{ALLEX ORNELLAS}

Mestre em Geografia Humana - USP

allexornellas88@gmail.com 